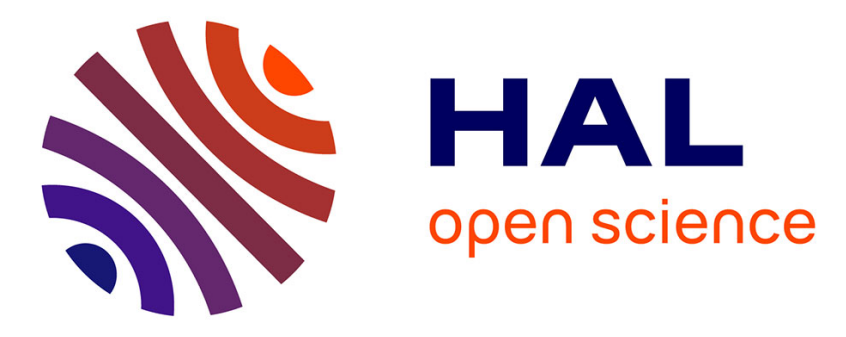

\title{
Design, fabrication and physical analysis of TiN/AlN deep UV photodiodes
}

Hassan Ali Barkad, Ali Soltani, Maghnia Mattalah, J-C Gerbedoen, Michel

Rousseau, Jean-Claude de Jaeger, Ali Benmoussa, Vincent Mortet, Ken Haenen, Brahim Benbakhti, et al.

\section{To cite this version:}

Hassan Ali Barkad, Ali Soltani, Maghnia Mattalah, J-C Gerbedoen, Michel Rousseau, et al.. Design, fabrication and physical analysis of TiN/AIN deep UV photodiodes. Journal of Physics D: Applied Physics, 2010, 43 (46), pp.465104. 10.1088/0022-3727/43/46/465104 . hal-00569746

\section{HAL Id: hal-00569746 https://hal.science/hal-00569746}

Submitted on 25 Feb 2011

HAL is a multi-disciplinary open access archive for the deposit and dissemination of scientific research documents, whether they are published or not. The documents may come from teaching and research institutions in France or abroad, or from public or private research centers.
L'archive ouverte pluridisciplinaire HAL, est destinée au dépôt et à la diffusion de documents scientifiques de niveau recherche, publiés ou non, émanant des établissements d'enseignement et de recherche français ou étrangers, des laboratoires publics ou privés. 


\title{
Design, fabrication and physical analysis of TiN/AIN deep UV photodiodes
}

H. A. Barkad ${ }^{1}$, A. Soltani ${ }^{1}$, M. Mattalah ${ }^{1}$, J-C. Gerbedoen ${ }^{1}$, M. Rousseau ${ }^{1}$, J-C. De Jaeger ${ }^{1}$

${ }^{1}$ IEMN, UMR-CNRS 8520, Avenue Poincaré, Université de Lille1, 59652 Villeneuve d'Ascq, France

A. BenMoussa ${ }^{2}$

${ }^{2}$ Royal Observatory of Belgium (ROB, STCE), Circular Avenue 3, B-1180 Brussels, Belgium

V. Mortet ${ }^{3}$, K. Haenen ${ }^{3}$

${ }^{3}$ Institute for Materials Research, Hasselt University, Wetenschapark 1, B-3590 Diepenbeek, Belgium IMEC vzw, Division IMOMEC, Wetenschapark 1, B-3590 Diepenbeek, Belgium

B. Benbakhti ${ }^{4}$

${ }^{4}$ DEEE, Rankine Building, Oakfield Avenue. University of Glasgow, G12 8LT Glasgow, Scotland, UK

M. Moreau ${ }^{5}$

${ }^{5}$ LASIR, USTL, C5, BP 69, 59652 Villeneuve d'Ascq Cedex, France

R. Dupuis ${ }^{6}$

${ }^{6}$ CCS-SECE, Georgia Institute of Technology, 777 Atlantic Drive NW, Atlanta, GA 30332-0250, USA

A. Ougazzaden ${ }^{7}$

${ }^{7}$ Georgia Tech-Lorraine (GTL), UMI 2958 GT-CNRS, 2-3 rue Marconi, 57070 Metz, France

\begin{abstract}
Deep-ultraviolet solar-blind photodiodes based on high-quality AIN films grown on sapphire substrates with a metal-semiconductor-metal configuration were simulated and fabricated. The Schottky contact is based on TiN metallisation. The material is characterised by micro-Raman spectroscopy and X-ray diffraction technique. The detector presents extremely low dark current of 100fA at $-100 \mathrm{~V}$ DC bias for a device area of $3.1 \mathrm{~mm}^{2}$. It also exhibits a rejection ratio between $180 \mathrm{~nm}$ and $300 \mathrm{~nm}$ of three orders of magnitude with a very sharp cut-off wavelength at $203 \mathrm{~nm}(\sim 6.1 \mathrm{eV})$. The simulation, based on a 2D energy-balance model using $\mathrm{COMSOL}^{\circledR}$ software, permits to help the designer for the optimum topology determination by means of physical studies. The measurement results are in good agreement with the model predictions.
\end{abstract}

Keywords: Photodiodes, AIN, deep UV, Simulation.

\footnotetext{
* Corresponding author: ali.soltani@iemn.univ-lille1.fr
} 


\section{Introduction}

Solar-blind deep-ultraviolet (DUV) photodetectors are able to operate at high temperature and in harsh environment thanks to their wide band gap structure. These devices present a variety of potential applications in the fields of automotive, aerospace, and military industries, as well as in environmental and biological research. These applications require high-performance solar-blind photodetectors with low dark current and high UV responsivity. DUV photodetectors fabricated from various wide band gap semiconductors such as wurtzite aluminium nitride (WAIN) [1], cubic boron nitride (cBN) [4] and diamond [5], were reported recently.

AIN is the only semiconductor with a large direct band gap $(\sim 6.1 \mathrm{eV})$ and it is available due to recent advances in epitaxial growth techniques [6] with very high quality epilayers obtained by metalorganic vapour physical epitaxy (MOVPE). In this paper, the design of the photodiodes is optimized by means of a 2D energy balance simulation based on $\mathrm{COMSOL}^{\circledR}$ software.

The fabricated devices have a Metal/Semiconductor/Metal (MSM) configuration with circular interdigitated electrodes. The device's spectral response reveals a very sharp cut-off wavelength at $203 \mathrm{~nm}(\sim 6.1 \mathrm{eV})$

\section{Material characterization}

AIN films are deposited on sapphire $\left(\mathrm{Al}_{2} \mathrm{O}_{3}\right)$ substrate by MOVPE. The growth temperature is $1100^{\circ} \mathrm{C}$ under 100Torr growth pressure. Trimethylaluminum and ammonia are used as the source materials and the carrier gas is hydrogen [6]. The AIN wurtzite structure belongs to the space group $C_{60}^{4}$ $\mathrm{P}_{3} / \mathrm{mmc}$, associated to the irreducible representation $\Gamma=A_{1}+2 \mathrm{~B}_{1}+\mathrm{E}_{1}+2 \mathrm{E}_{2}$ [7]. Crystalline phases and growth directions of AIN films were determined by $\theta / 2 \theta$ X-Ray Diffraction (XRD) with CuK $\alpha$ $(\mathrm{k}=1.540598 \AA)$ radiation operated at $40 \mathrm{kV}$ and $30 \mathrm{~mA}$. The rocking curve scan was performed with a detector at $2 \theta=36.1^{\circ}$ corresponding to the $2 \mathrm{H}$-AIN (0002) reflection (JCPDS c25-1133) when the sample orientation $\theta$ was varied from $5^{\circ}$ to $30^{\circ}$. 
The FWHM of the (0002) peak measured in the $\theta-2 \theta$ XRD pattern of AIN film is $0.77^{\circ}$ and its associated rocking curve $0.3^{\circ}$. The thickness of the thin film is $820 \mathrm{~nm}$.

The material quality is crucial since the optical performance in the extreme UV (EUV) is strongly influenced by the surface characteristics. High quality active layer is required and the thickness for total absorption should be optimal to obtain less defects, crack-free layers, low roughness, and good structural homogeneity. The doping level of the active layer is also one of the most critical parameters and should be below $10^{15} \mathrm{~cm}^{-3}$ in order to achieve a depletion reach-through region for a reasonable electrode gap spacing and very low dark current.

Micro-Raman spectra are obtained using a Jobin Yvon spectrometer with three excitation sources at $\lambda=266 \mathrm{~nm}, 514 \mathrm{~nm}$ and $785 \mathrm{~nm}$ (see Figure 1). Optical modes marked by a star and a square correspond to sapphire substrate and the AIN thin film respectively. All the TO and LO modes of AIN and sapphire can be seen on the spectra of Danidov et al. [7] and McNeil et al. [8] demonstrating the crystalline state of the deposited AIN films. Table 1 gives a comparison of our results with those of references [7] and [8]. The spectrum under UV (@ 266nm) excitation exhibits clearly the $A_{1}(T O)$ at $621 \mathrm{~cm}^{-1}$, the $\mathrm{E}_{2}{ }^{2}(\mathrm{TO})$ at $660 \mathrm{~cm}^{-1}$ and the $\mathrm{A}_{1}(\mathrm{LO})$ at $891 \mathrm{~cm}^{-1}$. The $\mathrm{E}_{1}{ }^{2}$ mode at $247 \mathrm{~cm}^{-1}$ is only observable under visible $(\lambda=514 \mathrm{~nm})$ or near infrared $(\lambda=785 \mathrm{~nm})$. These values are close to those of AIN crystal $[7,8]$.

\section{Modelling}

In order to design and fabricate AIN based photodetectors for solar-blind applications, a 2D energybalance model using $\mathrm{COMSOL}^{\circledR}$ software was developed. This model is based on the conservation equations deduced from Boltzmann's equation and coupled to Poisson's equation as such:

$\operatorname{div}(-\varepsilon \operatorname{gradV})=q\left(n-p+N_{A}{ }^{+}-N_{D}{ }^{-}\right)$

where $\varepsilon$ is the permittivity, $\mathrm{n}$ the electron density, $\mathrm{q}$ is the absolute electron charge, $\mathrm{N}_{\mathrm{A}}^{+}$et $\mathrm{N}_{\mathrm{D}}^{+}$ correspond ionized acceptors and donors density respectively.

Charge conservation equations: 
For electrons: $\frac{\partial n}{\partial t}+\operatorname{div}\left(n \overrightarrow{v_{n}}\right)=G-U \quad$ with $\quad v_{n}=-\mu_{n}\left[n \vec{E}+\left(\frac{1}{n}\right) \operatorname{div}\left(n k_{B} T_{e}\right)\right]$,

For holes: $\frac{\partial p}{\partial t}+\operatorname{div}\left(n \overrightarrow{v_{p}}\right)=G-U$ with $\quad v_{p}=\mu_{p}\left[p \overrightarrow{E-}\left(\frac{1}{p}\right) \operatorname{div}\left(p k_{B} T_{e}\right)\right]$

Where $G$ corresponds to electron-hole generation which is defined as: $G(x)=\phi(1-\Re) \alpha e^{-\alpha x}$ with $\Re(\lambda)$ the reflection coefficient and $\alpha(\lambda)$, the absorption coefficient versus wavelength. $\mu$ is the carriers mobility.

$U$ is the bulk recombination rate, defined as: $U=U_{\text {rad }}+U_{S R H}+U_{A u g}$, where $U_{S R H}$ corresponds to ShockleyRead-Hall rate recombination, $U_{\text {rad }}$ is the radiative recombination rate and $U_{\text {Aug }}$ is the Auger recombination rate.

The equations governing the energy flux are for electrons:

$\frac{\partial(n w)}{\partial t}=-\operatorname{div}\left[\left(w+k_{B} T_{e}\right) \cdot n \vec{v}_{n}\right]-\overrightarrow{n v_{n}} \vec{E}-\frac{n\left(w-w_{0}\right)}{\tau_{w}(w)}$, where $\tau_{w}$ is the energy relaxation time and $\mathrm{w}$ is the average energy related to the average velocity $\overrightarrow{\mathrm{v}}_{\mathrm{n}}$ and electron temperature $T_{\mathrm{e}}$. $w=\frac{1}{2} m^{*} v_{n}^{2}+\frac{3}{2} k_{B} T_{e}, w_{0}=\frac{3}{2} k_{B} T_{L}$, where $\mathrm{k}_{\mathrm{B}}$ is the Boltzmann's constant.

The transport parameters such as electron mobility, energy relaxation time and electron effective mass, are obtained from stationary Monte-Carlo simulations at room temperature. In the charge conservation equation, a generation term is included to take into account the light excitation. In this model, the number of electron-hole pairs created per absorbed photon is always unity in the wavelength region 170-425 $\mathrm{nm}$ (no secondary ionizations).

Furthermore, the band-to-band and Shockley-Read-Hall recombination effects are introduced. From this model, numerical simulations are carried out to study and optimize the device parameters such as detector geometry (gap spacing and electrodes width) and applied bias.

The studied structure is a MSM photodiode. The $2 \mathrm{D}$ simulation is carried out for a $300 \mathrm{~nm}$ thick AIN (unintentionally doped n-type at $10^{15} \mathrm{~cm}^{-3}$ ). The Schottky barrier height is $1 \mathrm{eV}$ and the total area is 
$(10 \times 10) \mu \mathrm{m}^{2}$ corresponding to a screen pixel whatever the considered topology. The photocurrent is calculated at $10 \mathrm{~V}$ bias $\left(\mathrm{V}_{\mathrm{AK}}\right)$ and the excitation power is fixed to $12 \mu \mathrm{W} / \mathrm{cm}^{2}$ from $170 \mathrm{~nm}$ to $425 \mathrm{~nm}$ according to the available data of the absorption coefficient and the reflectivity of AIN [10].The photodiode design was optimized considering the different main parameters. The first structure parameter to be optimized is the finger spacing for a given bias. Figure 2 shows the evolution of the device responsivity versus the electrode spacing for a symmetric design with two fingers. In the simulation, the electrode length is $0.2 \mu \mathrm{m}$ and the electrode spacing varies from $0.5 \mu \mathrm{m}$ (submicron structure) to $8 \mu \mathrm{m}$. The $\mathrm{V}_{\mathrm{AK}}$ bias between the two electrodes varies from $0.1 \mathrm{~V}$ up to $15 \mathrm{~V}$. The responsivity increases with this bias as it was expected and it is important to notice that it becomes higher for submicron devices [11].

The second structure parameter to be optimized is the finger width and device symmetry. For this study, different finger widths and device symmetries were simulated at 10V. Figure 3 shows the theoretical evolution of the responsivity versus the photon energy for different symmetric (sym) or asymmetric (asym) topologies as anode width $A_{L}$, cathode width $K_{L}$, number of fingers $N$, spacing between electrodes $S$ and the fill factor $K$ (active area/AIN area ratio). It can be noted that the responsivity increases when the finger width becomes submicron. The shadowing of the active area by the interdigitated contacts is the main drawback of the MSM-detector and results in loss of efficiency; furthermore the photoresponsivity is driven by the device fill factor becoming worst for the asym1 structure.

The dark current was also simulated for different spacing $\mathrm{S}$ showing a difference of several magnitudes for submicronic devices. Furthermore, an increase of this current versus $\mathrm{V}_{\mathrm{AK}}$ is observed for a lower value of $V_{A K}$ when the spacing drops. Consequently, a compromise must be found between the dark current level and the photoresponse.

To improve the device responsivity, semitransparent electrodes associated to a submicronic spaced and asymmetric topology can be considered on a large area device. All these solutions provide better 
detector characteristics in terms of dark current, UV/visible contrast, linearity and enhancement in responsivity.

\section{Device fabrication}

The devices were fabricated by depositing TiN/Au Schottky contacts [12] on the AIN surface using magnetron sputtering deposition. First, the AIN films are cleaned with an aceton/isopropanol standard process and then etched in $\mathrm{Ar}^{+}$plasma with a substrate bias of $-170 \mathrm{~V}$ for $90 \mathrm{~s}$ just before metal deposition in order to remove the native oxide on the AIN surface. Then, Au/TiN (150/5 nm) metallization is deposited on the AIN surface. An optical lithography is used to define the patterns. The electrodes are obtained after an Au etching with a potassium iodide solution ( $\mathrm{KI}$ ) and a TiN etching using $\mathrm{H}_{2} \mathrm{SO}_{4} / \mathrm{H}_{2} \mathrm{O}_{2}$ (piranha) solution. After deposition, the samples are annealed at $500^{\circ} \mathrm{C}$ for 40 min in $\mathrm{N}_{2}$ atmosphere to improve the stability of the electrode contacts and to form the Schottky contact. To achieve high homogeneity of the electric field between the contacts, the electrodes are patterned with a circular interdigitated configuration (see Figure 4). The diameter of the devices varies from 1 to $3 \mathrm{~mm}$ diameter. The finger width is $2 \mu \mathrm{m}$, and the interspacing between the contact pads is $5 \mu \mathrm{m}$. The electrode fill factor is more than $62 \%$. The advantage of this structure is a better noise factor in dark condition compared to submicronic devices [13].

\section{Results and discussion}

Current-voltage (I-V) characteristics are obtained using an Agilent $4155 \mathrm{C}$ with femtoampere (fA) resolution. Figure 5 shows the typical I-V characteristics of AIN-based MSM detectors measured in dark at room temperature in $\mathrm{N}_{2}$ atmosphere before and after annealing. The device exhibits a very low dark current around $100 \mathrm{fA}$ at $\pm 100 \mathrm{~V}$ bias after annealing. The differential resistance measured between two fingers at a distance of $8 \mu \mathrm{m}$, varies from $2.1 \times 10^{14} \Omega$ to $1.5 \times 10^{15} \Omega$ before and after annealing, respectively between $\mathrm{OV}$ and $\pm 100 \mathrm{~V}$ bias. The fabricated device exhibits a breakdown voltage $\left(\mathrm{V}_{\mathrm{BR}}\right)$ higher than $100 \mathrm{~V}$ corresponding to an electric field of $125 \mathrm{kV} / \mathrm{cm}$. 
Figure 6a shows the responsivity spectral measurement carried out on $2 \mathrm{~mm}$ diameter devices at $\pm 100 \mathrm{~V}$ DC bias, in the wavelength range from $180 \mathrm{~nm}$ to $300 \mathrm{~nm}(6.85 \mathrm{eV}$ to $4 \mathrm{eV})$. The AIN MSM photodiodes have a peak responsivity around $2 \times 10^{-3} \mathrm{~A} / \mathrm{W}$ at $200 \mathrm{~nm}$ and a very sharp cut-off around $203 \mathrm{~nm}(6.1 \mathrm{eV})$. This cut-off wavelength is close to AIN based MSM photodetectors obtained by Dahal et $a l$. [14]. A rejection ratio of more than three orders of magnitude is observed between 200 $\mathrm{nm}$ and $300 \mathrm{~nm}$. With our responsivity of $2 \mathrm{~mA} / \mathrm{W}$, the experimental specific detectivity @ $200 \mathrm{~nm}$ $\left(\mathrm{V}_{\mathrm{AK}}= \pm 100 \mathrm{~V}\right)$ correspond to $1.054 \times 10^{14} \mathrm{~cm}^{2} \mathrm{H}^{1 / 2} / \mathrm{W}$.

Note that different solar-blind UV photodetectors based on wide band gap semiconductors have been reported. MSM diamond photoconductor [5] presented a rejection ratio of $1.6 \times 10^{4}$ between $210 \mathrm{~nm}$ (maximum photoresponse of $48 \mathrm{~mA} / \mathrm{W}$ ) and $400 \mathrm{~nm}$ at $5 \mathrm{~V}$ bias ( $\mathrm{S}=5$ and $\mathrm{W}=2 \mu \mathrm{m}$ ). MSM photodiode fabricated on CBN [4] films grown on silicon substrate showed at -30V a rejection ratio of four order of magnitude between the maximal response (i.e. $180 \mathrm{~nm}, 21 \mathrm{~mA} / \mathrm{W}$ ) and $250 \mathrm{~nm}(\mathrm{~S}=5$ and $\mathrm{W}=2 \mu \mathrm{m}$ ). Finally AIN MSM photodiode [3] presented a rejection ratio of $1.2 \times 10^{4}$ between 200 $\mathrm{nm}$ (maximum photoresponse of $4.5 \mathrm{~mA} / \mathrm{W}$ ) and $360 \mathrm{~nm}$ at $30 \mathrm{~V}$ bias ( $\mathrm{S}=4$ and $\mathrm{W}=2 \mu \mathrm{m})$.

Spectra of the sub-band gap absorption are usually decomposed into "band to defect" and "band to tail" type transitions. In the first case, the photocurrent $I_{p h}$ proportionally varies to the capture cross section of traps by the relationship: $\sigma(h v) \equiv \Delta \mathrm{I}_{\mathrm{ph}} /\left(\mathrm{I}_{\text {dark }} \cdot \phi_{0} \cdot \mathrm{t}\right)(1)$ with $\Delta \mathrm{I}_{\mathrm{ph}}=\mathrm{I}_{\mathrm{ph}}-\mathrm{I}_{\text {dark. }}$. The illumination time is $62 \mathrm{~ms}$ and the incident photon flux per $\mathrm{cm}^{2}$ is $\phi_{0}=\mathrm{P} /(\mathrm{S} . \mathrm{E})$ where $\mathrm{P}$ is the incident power and $\mathrm{E}$ the photon energy. The active area is equal to $2.2 \mathrm{~mm}^{2}$. The results of the fitting parameters obtained from Inkson's model [15] are listed in Table 2. Three trap levels are deduced at 3.5, 5.45 and $5.8 \mathrm{eV}$ up to the valence band. The capture cross sections of $\mathrm{ET}_{2}$ and $\mathrm{ET}_{3}$ show that those transitions are indirect. The transition $\mathrm{ET}_{3}$ is responsible for the exponential increase at the absorption edge commonly described by the Urbach's rule [16] and follows the relation: $I_{p h}(E)=I_{p h 0} \exp \left[\left(E-E_{G}\right) / E_{U}\right](2)$, where $I_{p h o}$ is a material parameter, $E_{G}$ is the band gap and $E_{U}$ is the Urbach energy representing the width of the exponential absorption edge. In the particular case of III-nitrides, the Urbach's tale is mainly a consequence of the carrier interaction with lattice and lattice imperfections (defects, 
impurities...). The photocurrent curve is fitted with the Urbach expression (2) with the different parameters $E_{G}, I_{p h 0}$ and $E_{U}$ corresponding to $6 \mathrm{eV}, 4,45 \times 10^{-4}$ and $0.13 \mathrm{eV}$, respectively. Figure $6 \mathrm{~b}$ corresponds to the simulated responsitivity using the optical constants of single crystal of AIN with two light polarization states: $E \perp c$ and $E / / c$ (c is the optical axis). Data for simulation are taken from Adachi [10].The responsivity curve is fitted from (2) with different parameters $E_{G}, I_{\text {pho }}$ and $E_{U}$ corresponding to $6.1 \mathrm{eV}, 5.22 \mathrm{~mA} / \mathrm{W}$ and $0.22 \mathrm{eV}$, respectively for $\mathrm{E} \perp \mathrm{c}$ and $5.95 \mathrm{eV}, 2.5 \mathrm{~mA} / \mathrm{W}$ and $0.47 \mathrm{eV}$ for $\mathrm{E} / / \mathrm{c}$. The experimental values are close to the theoretical predictions considering bulk AIN material showing a good crystallographic quality of the deposited thin films.

\section{Conclusion}

In summary, solar-blind DUV MSM photodetectors were simulated and fabricated on high quality wurtzite AIN films by MOVPE with a circular inter-digitated electrode design. The device topology is optimized from a 2D energy-balance simulation where the generation and recombination terms are included. The Schottky contact is based on a TiN metallisation process. A very low dark current around $100 \mathrm{fA}$ at $\pm 100 \mathrm{~V} D$ bias is obtained. The photodetectors show a high sensitivity to DUV light and a sharp cut-off wavelength around $203 \mathrm{~nm}$, close to the band gap of bulk AIN. This corresponds to the shortest value reported up to now on this semiconductor. The rejection ratio (the ratio of responsivity between $200 \mathrm{~nm}$ and $300 \mathrm{~nm}$ ) is found to be over three orders of magnitude. 


\section{References}

[1] R. Dahal, J. Li, Z. Y. Fan, M. L. Nakarmi, T. M. Al Tahtamouni, J. Y. Lin, H. X. Jiang., Phys. Stat. Sol. (c) 5 (6) (2008) 2148-2151.

[2] J. Li, Z.Y. Fan, R. Dahal, M.L. Nakarmi, J.Y. Lin and H.X. Jiang, Appl. Phys. Lett. 89 (2006) 213510.

[3] A. BenMoussa, J. F. Hochedez, R. Dahal, J. Li, J. Y. Lin, H. X. Jiang, A. Soltani, J.-C. De Jaeger, U. Kroth, M. Richter, APL 92 (2008) 22108.

[4] A. Soltani, H.A. Barkad, M. Mattalah, B. Benbakhti, J.-C. De Jaeger, Y. M. Chong, Y. S. Zou, W. J. Zhang, S.T. Lee, A. BenMoussa, B. Giordanengo, J.-F. Hochedez, APL 92 (2008) 053501.

[5] A. BenMoussa, A. Soltani, K. Haenen, U. Kroth, V. Mortet, H. A. Barkad, D. Bolsee, C. Hermans, M. Richter, J.-C De Jaeger, J.-F. Hochedez, Semiconductor Science and Technology 23 (2008) 035026.

[6] H. J. Kim, S. Choi, D. Yoo, J.-H. Ryou, R. D. Dupuis, R. F. Dalmau, P. Lu, Z. Sitar, APL 93 (2008) 022103.

[7] V. Yu. Davydov, Yu. E. Kitaev, I. N. Goncharuk, A. N. Smirnov, J. Graul, O. Semchinova, D. Uffmann, M. B. Smirnov, A. P. Mirgorodsky, R. A. Evarestov, Phys. Rev. B 58 (19) (1998) 12899-12907.

[8] L. E. McNeil, M. Grimsditch, R. H. French, J. Am. Ceram. Soc 76 (1993) 1132-1136.

[9] M. Kadleikova, J. Breza, M. Vesely, Microelectronics Journal 32 (12) (2001) 955-958.

[10] S. Adachi, "Optical Constants of Crystalline and Amorphous Semiconductors: Numerical Data and Graphical Information", Kluwer Academic, Boston 149 (1999).

[11] T. Palacios, E. Monroy, F. Calle, F. Omnès, APL 81 (10) (2002) 1902.

[12] J-C. Gerbedoen, A. Soltani, M. Mattalah, J-C. De Jaeger, H. Lahreche, A. Telia, submitted to APL.

[13] A. Navarro, C. Rivera J. Pereira, E. Muñoz, B. Imer, S. P. DenBaars and J. S. Speck, APL 94 (2009) 213512.

[14] R. Dahal, T. M. Al Tahtamouni, Z. Y. Fan, J. Y. Lin, and H. X. Jiang, APL. 90 (2007) 263505.

[15] J.C. Inkson, J. Phys. C, Solid State Phys. 14 (1981) 1093.

[16] F. Urbach Phys. Rev., 92 (1953) 1324. 


\section{Figure captions}

Table 1: Peak positions of Raman modes (in $\mathrm{cm}^{-1}$ ) of different wurtzite $\mathrm{AIN}$ and $\mathrm{Al}_{2} \mathrm{O}_{3}$ structures [7]. Our sample corresponds to the $\mathrm{AIN} / \mathrm{Al}_{2} \mathrm{O}_{3}$ structure.

Table 2: Results of the fitting parameters obtained from the fitting curve of Figure 7a. The different level of traps $\mathrm{ET}_{1}, \mathrm{ET}_{2}, \mathrm{ET}_{3}$ and the parameters $\mathrm{P}_{1}$ permit to determine the capture cross sections $(\sigma)$.

Figure 1: Micro-Raman spectra collected from the AlN film grown on a sapphire substrate. The squares are assigned to wurtzite AIN modes and the stars are assigned to sapphire substrate modes.

Figure 2: Responsivity evolution versus the electrode spacing for a symmetric structure with two 0.2 $\mu \mathrm{m}$ length electrodes for different biases under radiation excitation $(\lambda=6.1 \mathrm{eV})$.

Figure 3: Responsivity versus the photon energy for different topologies: $A_{L}$ is the anode length, $K_{L}$ is the cathode length, $\mathrm{N}$ is the electrode number and $\mathrm{K}$ is the corresponding fill factor. The distance $\mathrm{S}$ between 2 electrodes varies between $0.5 \mu \mathrm{m}$ and $1 \mu \mathrm{m}$. $\mathrm{V}_{\mathrm{AK}}=10 \mathrm{~V}$.

Figure 4: Optical microscopy image of a $2 \mathrm{~mm}$ diameter AIN photodiode (a) and zoom view of the circular inter-digitated electrodes in the centre area (b).

Figure 5: Current-Voltage characteristics of a $2 \mathrm{~mm}$ diameter AIN photodiode measured in dark conditions at room temperature before and after annealing at $500^{\circ} \mathrm{C}$.

Figure 6: Spectral responsivity of an AIN MSM photodiode measured at $\pm 100 \mathrm{~V}$ DC bias under irradiation in the 180-300 $\mathrm{nm}$ range (a). Simulated responsivity from data [10] for two light polarization states $(E / / c$ and $E \perp c)(b)$. 


\begin{tabular}{|c|c|c|c||c|c|}
\hline $\begin{array}{c}\text { Optical modes } \\
\left(\mathrm{cm}^{-1}\right)\end{array}$ & $\begin{array}{c}\text { AlN bulk } \\
\text { single crystal [7] }\end{array}$ & $\begin{array}{c}\text { wAIN thin } \\
\text { film [7] }\end{array}$ & $\begin{array}{c}\text { AIN } \\
\text { (our sample) }\end{array}$ & $\begin{array}{c}\mathrm{Al}_{2} \mathrm{O}_{3} \text { Bulk } \\
\text { [9] }\end{array}$ & $\begin{array}{c}\mathrm{Al}_{2} \mathrm{O}_{3} \\
\text { (our sample) }\end{array}$ \\
\hline $\mathrm{E}_{2}\left(\right.$ low) $\mathrm{E}_{2}{ } \mathrm{~A}_{1}(\mathrm{TO})$ & 252 & 248 & 247 & 419 & 420 \\
\hline $\mathrm{E}_{1}(\mathrm{TO})$ & 614 & 610 & 621 & 431 & 435 \\
\hline $\mathrm{E}_{2}(\mathrm{high}) \mathrm{E}_{2}{ }^{2}$ & 660 & 670 & - & 445 & 452 \\
\hline $\mathrm{A}_{1}(\mathrm{LO})$ & 673 & 657 & 660 & 492 & - \\
\hline $\mathrm{E}_{1}(\mathrm{LO})$ & 893 & 890 & 891 & 600 & 580 \\
\hline
\end{tabular}

Table 1

\begin{tabular}{|c|c|c|c|c|}
\hline \multicolumn{2}{|c|}{ capture cross sections } & $\mathrm{E}_{\mathrm{T}}(\mathrm{eV})$ & $\mathbf{P}_{\mathbf{1}}$ & $\boldsymbol{\sigma}\left(\mathrm{cm}^{2}\right)$ \\
$\sigma_{\mathrm{C}}=\mathrm{P}_{1}\left(\mathrm{hv}-\mathrm{E}_{\mathrm{T} 1}\right)^{3 / 2} / \mathrm{hv}$ & $\mathrm{ET}_{1}$ & 3.5 & $2.2 \times 10^{-5}$ & - \\
\hline$\sigma_{\mathrm{C}}=\mathrm{P}_{1}\left(\mathrm{hv}-\mathrm{E}_{\mathrm{T} 2}\right)^{3 / 2} / \mathrm{hv}$ & $\mathrm{ET}_{2}$ & 5.45 & $6 \times 10^{-4}$ & $1.25 \times 10^{-11}$ \\
\hline$\sigma_{\mathrm{C}}=\mathrm{P}_{1}\left(\mathrm{hv}-\mathrm{E}_{\mathrm{T} 3}\right)^{3 / 2} / \mathrm{hv}$ & $\mathrm{ET}_{3}$ & 5.8 & 0.018 & $1.426 \times 10^{-11}$ \\
\hline
\end{tabular}

Table 2 


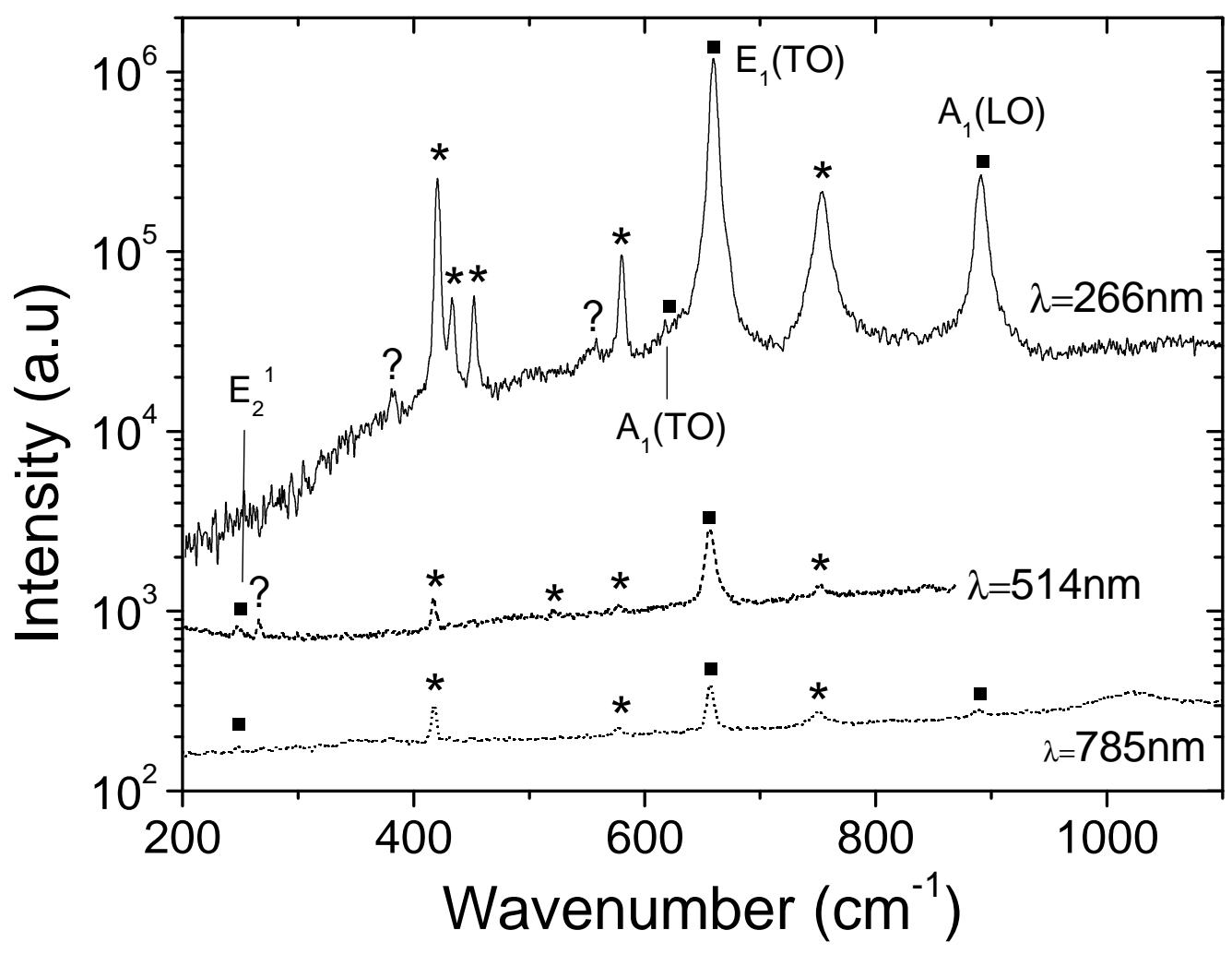

Figure 1 


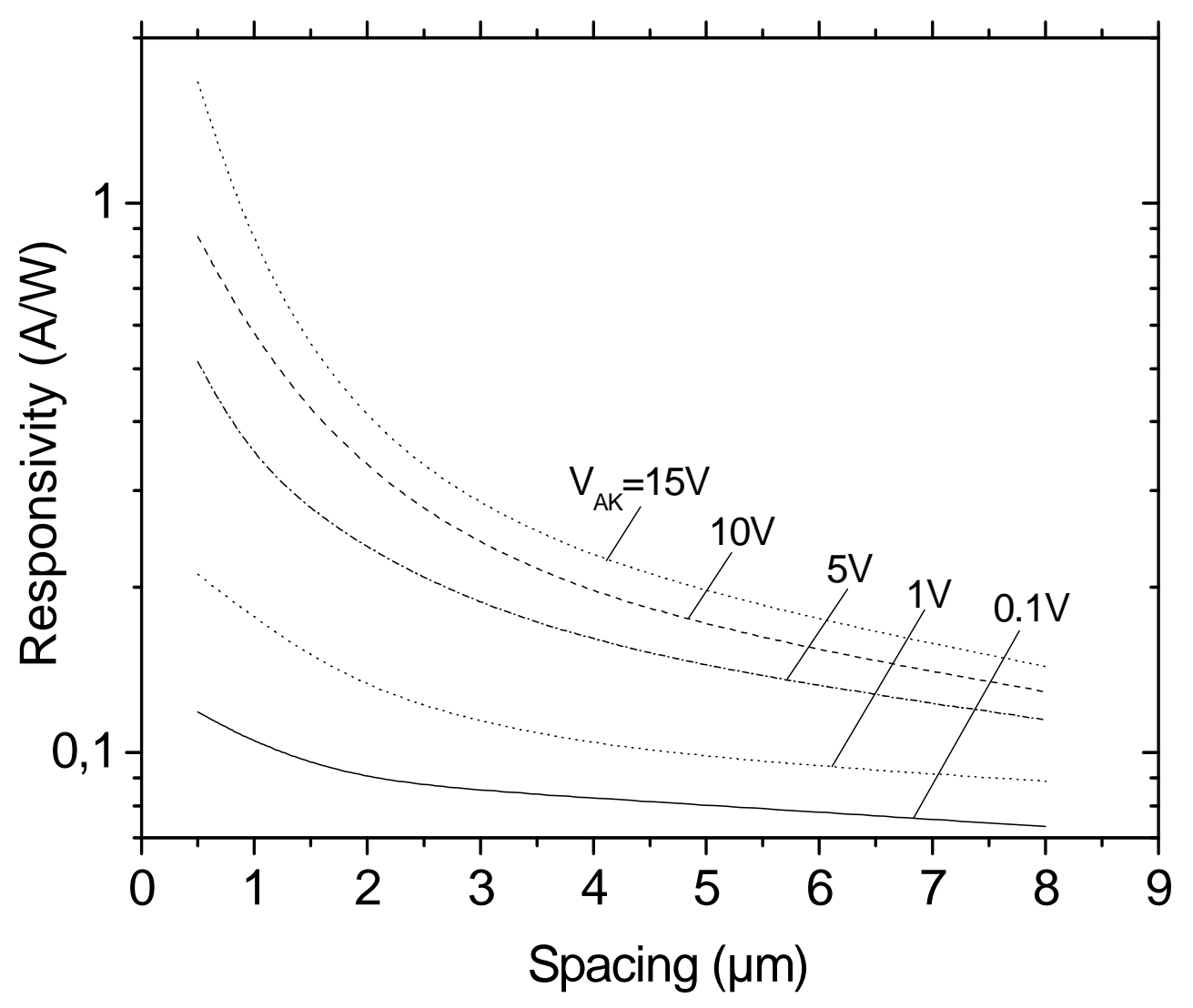

Figure 2 


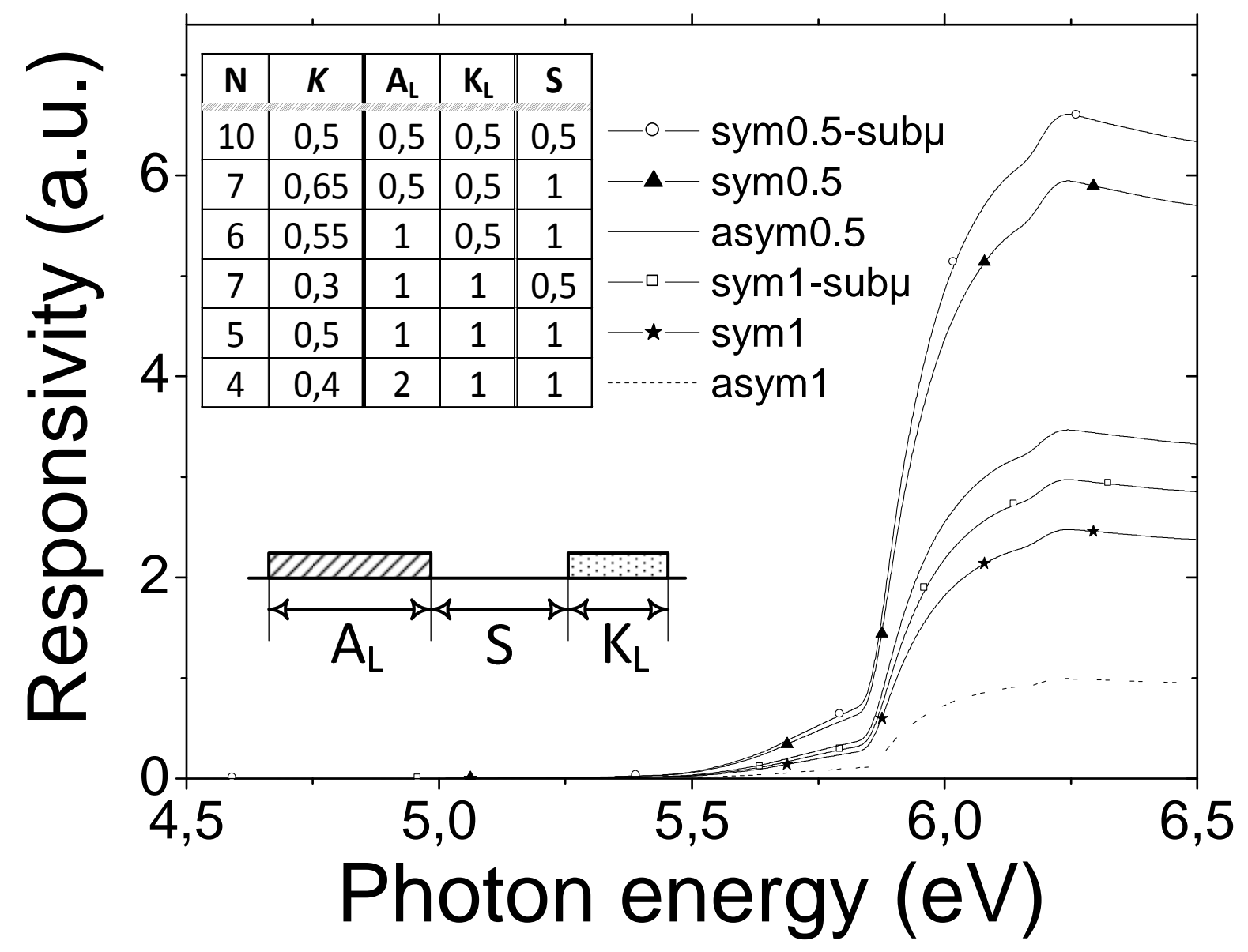

Figure 3 


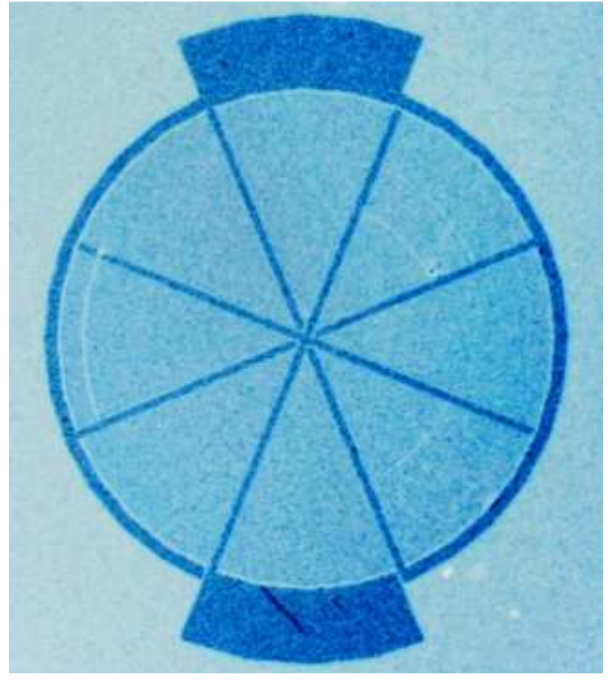

(a)

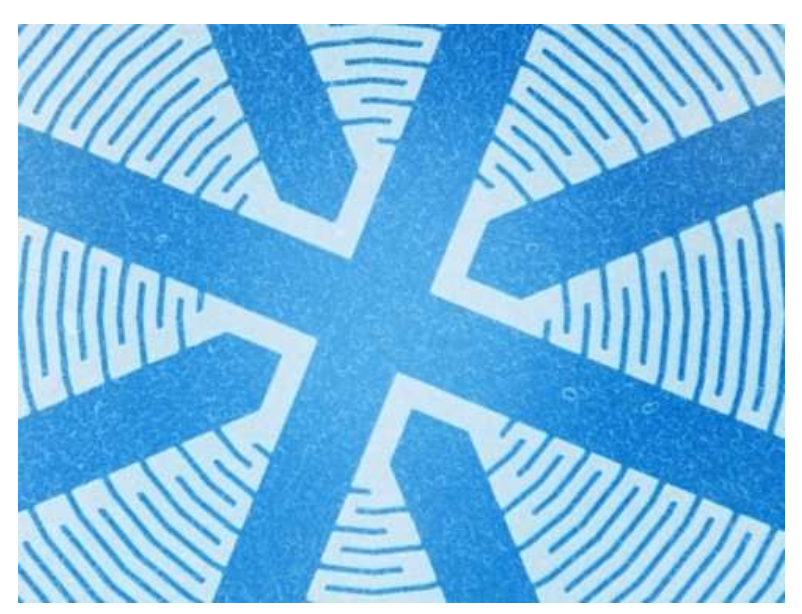

(b)

Figure 4 


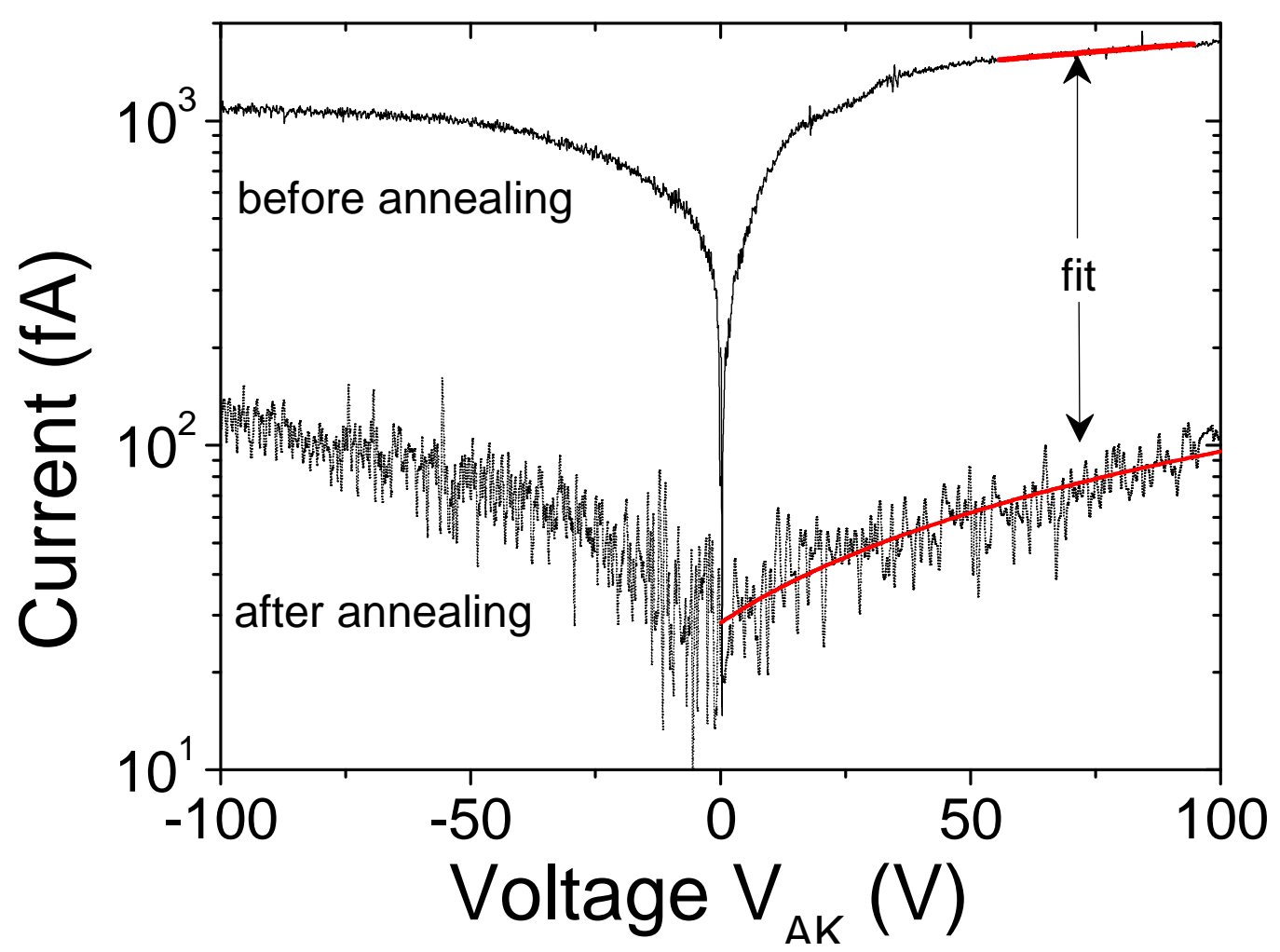

Figure 5 

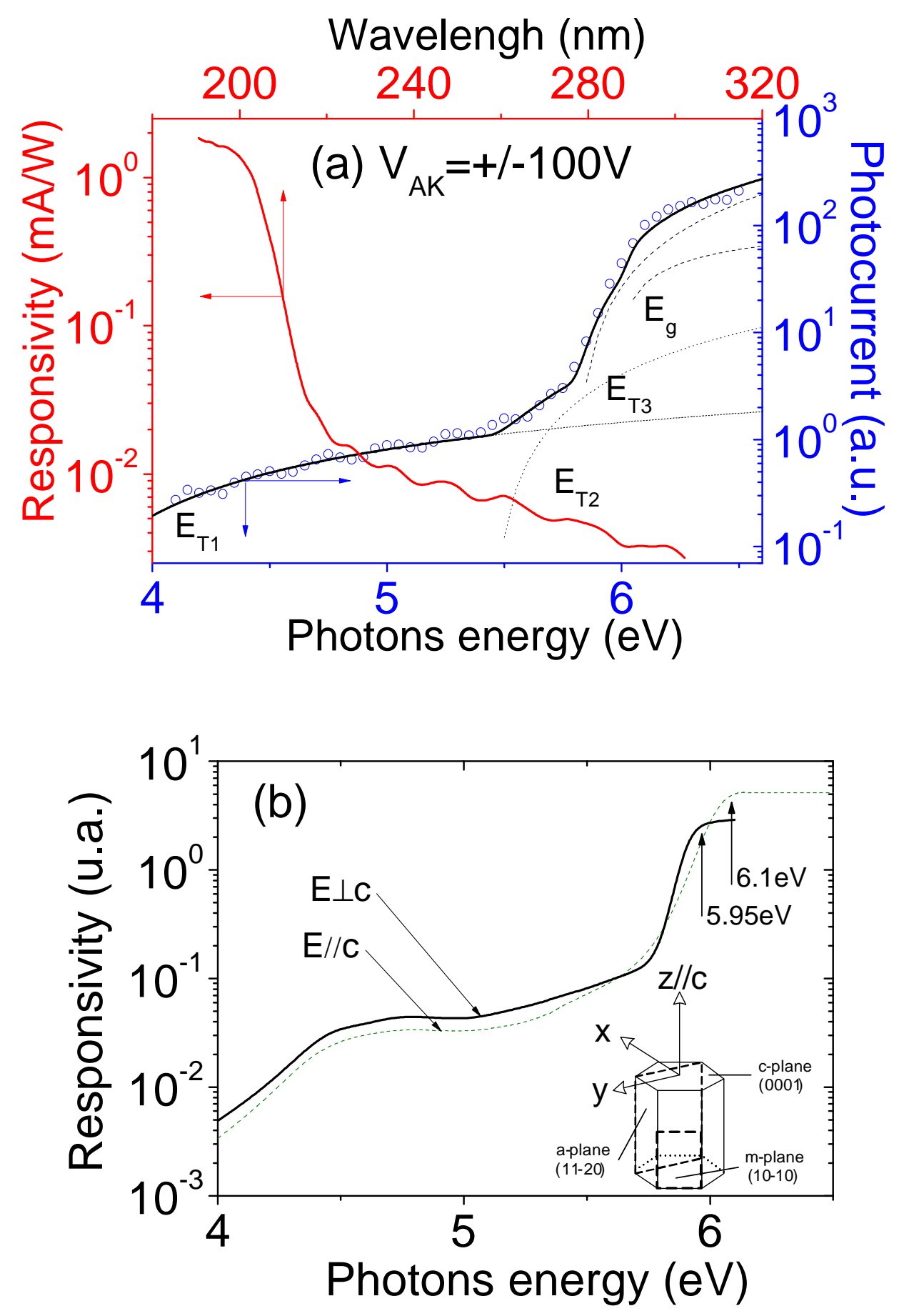

Figure 6 